OPEN ACCESS

Edited by:

Sanae Chiba,

Japan Agency for Marine-Earth Science and Technology, Japan

Reviewed by:

Robert Andrew Weller,

Woods Hole Oceanographic

Institution, United States

Detlef Stammer,

Universität Hamburg, Germany

*Correspondence:

Toste Tanhua

ttanhua@geomar.de

Specialty section:

This article was submitted to

Ocean Observation,

a section of the journal

Frontiers in Marine Science

Received: 15 November 2018

Accepted: 12 July 2019

Published: 20 August 2019

Citation:

Tanhua T, McCurdy A, Fischer A,

Appeltans W, Bax N, Currie K,

DeYoung B, Dunn D, Heslop E,

Glover LK, Gunn J, Hill K, Ishii M,

Legler D, Lindstrom E, Miloslavich $P$,

Moltmann T, Nolan G, Palacz A,

Simmons S, Sloyan B, Smith LM,

Smith N, Telszewski M, Visbeck M

and Wilkin J (2019) What We Have

Learned From the Framework for

Ocean Observing: Evolution of the

Global Ocean Observing System.

Front. Mar. Sci. 6:471.

doi: 10.3389/fmars.2019.00471

\section{What We Have Learned From the Framework for Ocean Observing: Evolution of the Global Ocean Observing System}

\author{
Toste Tanhua ${ }^{*}$, Andrea McCurdy ${ }^{2}$, Albert Fischer ${ }^{3}$, Ward Appeltans ${ }^{4}$, Nicholas Bax ${ }^{5,6}$, \\ Kim Currie ${ }^{7}$, Brad DeYoung ${ }^{8}$, Daniel Dunn 9,10, Emma Heslop $^{3}$, Linda K. Glover ${ }^{11}$, \\ John Gunn ${ }^{6}$, Katherine Hill'2, Masao Ishii ${ }^{13}$, David Legler ${ }^{14}$, Eric Lindstrom ${ }^{15}$, \\ Patricia Miloslavich ${ }^{6,16}$, Tim Moltmann ${ }^{6}$, Glenn Nolan ${ }^{17}$, Artur Palacz ${ }^{18}$, \\ Samantha Simmons ${ }^{19}$, Bernadette Sloyan ${ }^{5}$, Leslie M. Smith ${ }^{20}$, Neville Smith ${ }^{21}$, \\ Maciej Telszewski ${ }^{17}$, Martin Visbeck ${ }^{1}$ and John Wilkin ${ }^{22}$
}

${ }^{1}$ GEOMAR Helmholtz Centre for Ocean Research Kiel, Marine Biogeochemistry, Kiel, Germany, ${ }^{2}$ Cooperative Programs for the Advancement of Earth System Science, University Corporation for Atmospheric Research, Boulder, CO, United States, ${ }^{3}$ Global Ocean Observing System, Paris, France, ${ }^{4}$ Intergovernmental Oceanographic Commission of UNESCO, Oostende, Belgium, ${ }^{5}$ CSIRO and University of Tasmania, Hobart, TAS, Australia, ${ }^{6}$ Institute for Marine and Antarctic Studies, University of Tasmania, Hobart, TAS, Australia, ${ }^{7}$ National Institute for Water and Atmospheric Research, Dunedin, New Zealand, ${ }^{8}$ Department of Physics and Physical Oceanography, Memorial University, St. John's, NL, Canada, ${ }^{9}$ Nicholas School of the Environment, Duke University, Beaufort, NC, United States, ${ }^{10}$ School of Earth and Environmental Sciences, University of Queensland, Brisbane, QLD, Australia, ${ }^{11}$ Glover Works Consulting, Alexandria, VA, United States, ${ }^{12}$ World Meteorological Organization, Geneva, Switzerland, ${ }^{13}$ Meteorological Research Institute, Ibaraki, Japan, ${ }^{14}$ National Oceanic and Atmospheric Administration, Climate Program Office, Silver Spring, MD, United States, ${ }^{15}$ National Aeronautics and Space Administration, Washington, DC, United States, ${ }^{16}$ Departamento de Estudios Ambientales, Universidad Simón Bolivar, Caracas, Venezuela, ${ }^{17}$ European Global Ocean Observing System, Brussels, Belgium, ${ }^{18}$ International Ocean Carbon Coordination Project, Institute of Oceanology, Polish Academy of Sciences, Sopot, Poland, ${ }^{19}$ Marine Mammal Commission, Bethesda, MD, United States, ${ }^{20}$ Your Ocean Consulting, LLC, Knoxville, TN, United States, ${ }^{21}$ GODAE Ocean Services, Melbourne, VIC, Australia, ${ }^{22}$ Department of Marine and Coastal Sciences, Rutgers University, New Brunswick, NJ, United States

The Global Ocean Observing System (GOOS) and its partners have worked together over the past decade to break down barriers between open-ocean and coastal observing, between scientific disciplines, and between operational and research institutions. Here we discuss some GOOS successes and challenges from the past decade, and present ideas for moving forward, including highlights of the GOOS 2030 Strategy, published in 2019. The OceanObs'09 meeting in Venice in 2009 resulted in a remarkable consensus on the need for a common set of guidelines for the global ocean observing community. Work following the meeting led to development of the Framework for Ocean Observing (FOO) published in 2012 and adopted by GOOS as a foundational document that same year. The FOO provides guidelines for the setting of requirements, assessing technology readiness, and assessing the usefulness of data and products for users. Here we evaluate successes and challenges in FOO implementation and consider ways to ensure broader use of the FOO principles. The proliferation of ocean observing activities around the world is extremely diverse and not managed, or even overseen by, any one entity. The lack of coherent governance has resulted in duplication and varying degrees of clarity, responsibility, coordination and data sharing. GOOS has had considerable success over the past decade in encouraging voluntary collaboration across much of this broad community, including increased use 
of the FOO guidelines and partly effective governance, but much remains to be done. Here we outline and discuss several approaches for GOOS to deliver more effective governance to achieve our collective vision of fully meeting society's needs. What would a more effective and well-structured governance arrangement look like? Can the existing system be modified? Do we need to rebuild it from scratch? We consider the case for evolution versus revolution. Community-wide consideration of these governance issues will be timely and important before, during and following the OceanObs'19 meeting in September 2019.

Keywords: ocean observing, governance, framework for ocean observing, sustainable development, multidisciplinary, international

\section{THE MANDATE FOR SUSTAINED OCEAN OBSERVING}

The ocean affects humans in many ways, regardless of where we live. It continues to produce most of the oxygen we breathe and is the primary controller of the global climate that makes this planet habitable. It provides humans with food, materials, energy, transportation, and recreation.

However, the ocean is also the source of many hazards, both natural and anthropogenic induced including increasingly strong hurricanes and severe coastal flooding, tsunamis, storm surges, sea level rise, toxic algal blooms and other pollution. An ability to observe and forecast the ocean and its links to weather, climate and biogeochemical phenomena are required to mitigate risks via improved early warning systems.

Assessing progress of the United Nations (UN) Agenda 2030 and its Sustainable Development Goal 14 to, "conserve and sustainably use the oceans, seas and marine resources for sustainable development," and many of the other 17 Sustainable Development Goals will require sustained ocean data. There will be a profound need for essential ocean information to guide policy and progress toward both local public safety needs as well as the range of internationally-agreed upon goals.

The international community has identified global goals related to sustainable development, climate change, and disaster risk reduction that all require systematic ocean observations:

- The UN Sustainable Development Goals: At the June 2017 UN Ocean Conference, governments called for more resources for sustained ocean and coastal observation, "in order to increase our knowledge of the ocean, to better understand the relationship between climate and the health and productivity of the ocean, to strengthen the development of coordinated early warning systems on extreme weather events and phenomena, and to promote decision-making based on the best available science."

- Improved monitoring of marine ecosystems also supports global goals under the Convention for Biodiversity, regional frameworks such as Europe's Marine Strategy Framework Directive, and assessments like those produced by the Intergovernmental Science-Policy Platform for Biodiversity and Ecosystem Services (IPBES) and the World Ocean Assessment.
- The UN Framework Convention on Climate Change (UNFCCC) and the Paris Agreement (2015) note the importance of ensuring the integrity of all ecosystems, including those in the ocean, and call on countries to strengthen, "systematic observation of the climate system and early warning systems, in a manner that informs climate services and supports decision-making." Ocean observations are also essential to the validation of climate projections assessed by the Intergovernmental Panel for Climate Change.

Governments and policymakers are facing complex decisions that require information from sustained ocean observations. We lack both the observations and integration necessary to fully meet these needs. In many areas, sustained ocean observations are simply too infrequent, sparse, inadequate, or imprecise. A step-change is required in worldwide investment in order to take advantage of the changes made possible by increasing requirements and the expansion of technological developments and the adoption of open data policies. The improved understanding of the ocean based on decades of scientific effort, in concert with a recognized need for continued coordination of efforts to observe, analyze, understand and predict the ocean will assist in the realization of a return on this important societal investment.

\section{THE GLOBAL OCEAN OBSERVING SYSTEM (GOOS) AND THE FRAMEWORK FOR OCEAN OBSERVING (FOO)}

GOOS was established in 1991 by the Member States of the Intergovernmental Oceanographic Commission (IOC) of the United Nations Educational, Scientific and Cultural Organization (UNESCO), with the World Meteorological Organization (WMO), UN Environment, and the International Science Council (ISC) later joining as sponsors.

Over the past quarter-century, the GOOS community and partners have worked well in coordinating global ocean climate observing and information products and in supporting observations for operational forecast systems. More recently, GOOS has had a growing focus on an integrated global observing 
system including a wider range of data types and serving a broader range of users, consisted with the Framework of Ocean Observing (FOO, Lindstrom et al., 2012).

In 2012, the IOC General Assembly unanimously endorsed all the FOO recommendations. A new GOOS Steering Committee was established to replace the IOC Intergovernmental Committee on GOOS and its supporting GOOS Scientific Steering Committee. Three new recommended expert panels were formed, and the GRA Council was reinvigorated.

\section{Origin and Early Accomplishments of the FOO}

The OceanObs'09 Conference ${ }^{1}$ in Venice, Italy achieved broad agreement on the need for interdisciplinary, internationally integrated ocean observations. Based on general consensus at the meeting, its 18 sponsors commissioned a working group of international program representatives to create a systematic approach for defining requirements for ocean observations, deciding appropriate technology for measurements, and assessing data standards and dissemination. The resulting Framework for Ocean Observing has been widely endorsed by the ocean observing community, and adopted formally by GOOS as a guiding document.

In addition to its extensive recommendations on the design of an enhanced ocean observing system, the FOO made two recommendations on governance:

- To simplify and strengthen the high-level governance of GOOS, establish a single, expertise-based Steering Committee reporting directly to the IOC officers and members; and,

- Establish two new GOOS Panels - for Biogeochemistry, and for Biology and Ecosystems, to complement the existing Observations of Ocean Physics and Climate Panel.

The FOO argues that it is essential that governance of the global ocean observing system reflect the needs and contributions of both the broad ocean observing system community (scientists, institutions, observing system managers), and the IOC member states who should represent their national and collectively the international community's interests, and users of ocean information. The changes to the GOOS Program governance made in 2012 were a step-change toward providing a balance between the interests of these two communities. However, since OceanObs'09 and the FOO the proliferation of consortia/organizations (the "acronym soup") that now share the broad ocean observing mission makes the governance challenge even more complex.

It is important to note that the 2012 IOC endorsement of the expanded GOOS focus has not resulted in increased IOC budgetary support. Indeed, in real terms core budgetary support for GOOS has declined. Operations of the significantly expanded work plans for GOOS have been funded through short term grants and financial support from various institutions and regional funding programs. This has driven a significant decentralization of GOOS efforts and weakens sustainability.

\footnotetext{
${ }^{1}$ http://www.oceanobs09.net/index.php
}

\section{Elements of the Framework for Ocean Observing}

The FOO provides a structure that allows ocean observing providers and users to engage in the system at various points. It traces the path from Inputs (e.g., essential ocean variables) to Processes (observations and maintenance), to Outputs (data and products). It has helped form an understanding of the elements of the system as a whole and has facilitated the activities of GOOS in many areas (Figure 1).

The common language and system design principles introduced by the FOO are:

- Essential Ocean Variables (EOVs)

- Requirements

- Observing system elements

- Data management and information products

- Readiness levels (for requirements, observations, and data and information)

- Incorporation of both coastal and open ocean observations

- Feedback loops addressing science challenges and social needs

\section{Elements of the GOOS}

The organization of GOOS is comprised of several key elements (see Figure 2).

\section{GOOS Steering Committee}

GOOS is guided by a Steering Committee, with 10 expert members appointed by the IOC Executive Secretary in consultation with sponsors, and five members selected by IOC regional electoral groups. The Steering Committee reports to the IOC Assembly and other sponsors, defines the GOOS work plan, and manages the structures that report to it.

\section{GoOS Office}

The GOOS Office, headquartered at the IOC, consists of a small core team with in-kind contributions from several supporting agencies. The Office supports the work and actions of the Steering Committee, panels, and implementation structures of GOOS, serving as a hub of communication, and point of contact for partners.

\section{Expert Panels}

Three panels for global ocean observing are focused on developing essential ocean variables (EOVs), evaluating success of the system, and synthesizing across the climate, operational services and ocean ecosystem health requirements. The three panels are: Physics (The Ocean Observations Physics and Climate panel, co-sponsored with the Global Climate Observing System, GCOS), Biogeochemistry (the International Ocean Carbon Coordination Project, IOCCP), and the Biology and Ecosystems Panel.

\section{The Observations Coordination Group}

The IOC/WMO Joint Technical Commission for Oceanography and Marine Meteorology (JCOMM) has an Observations Coordination Group (OCG) charged with reviewing, advising on, 


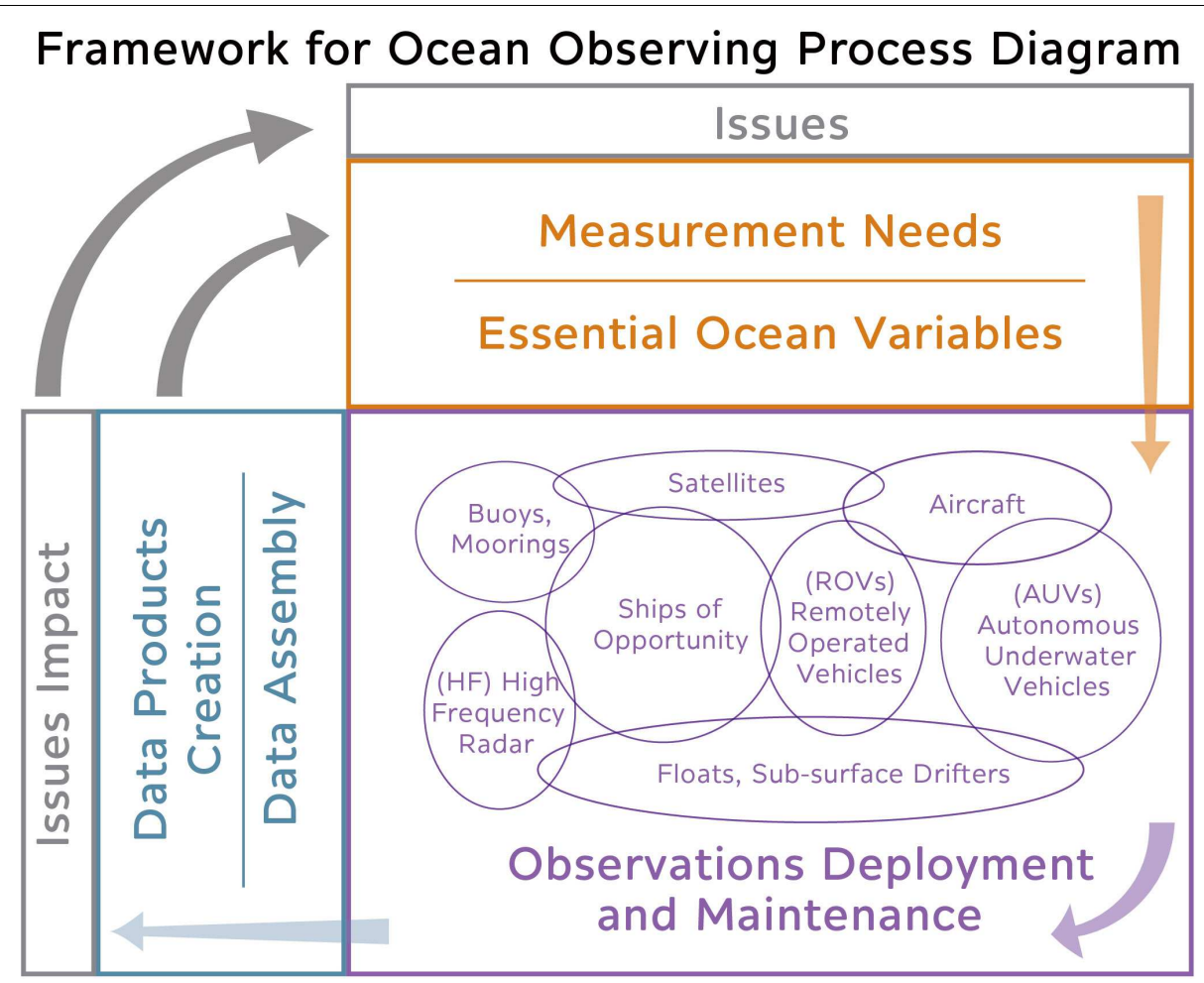

FIGURE 1 | Overview of the key elements in the Framework of Ocean Observing (FOO).

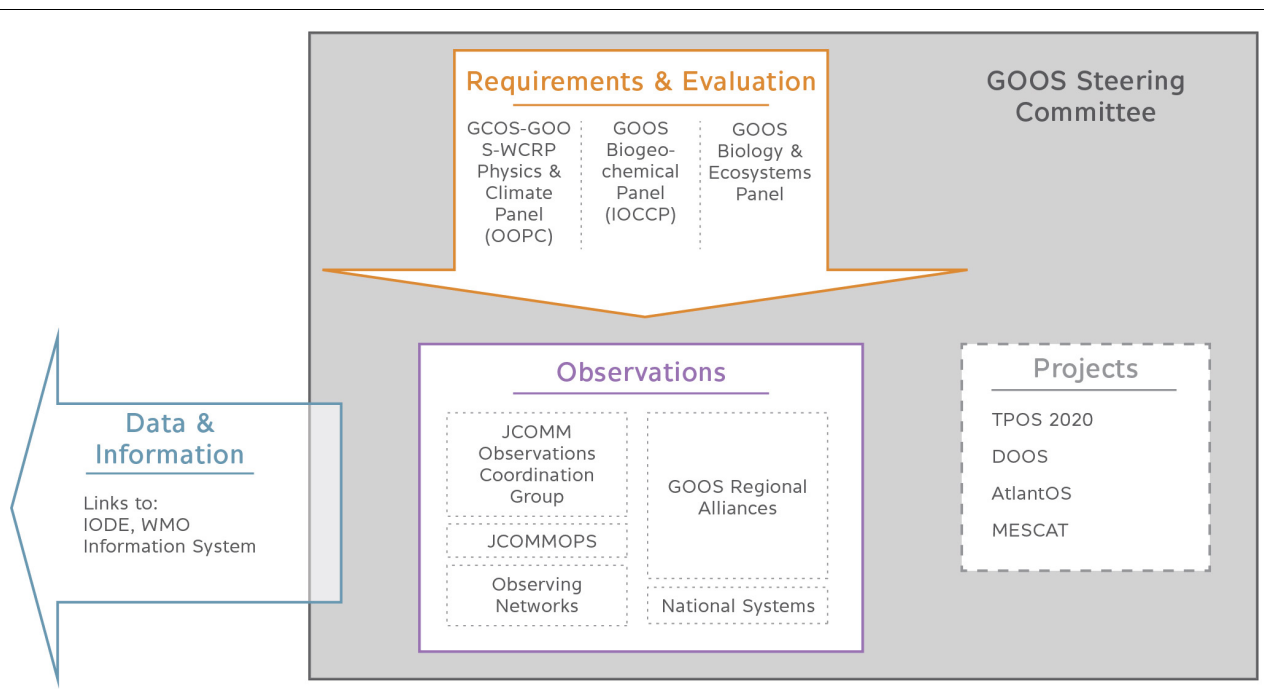

FIGURE 2 | Primary areas of activity and influence for key GOOS elements and linkages in 2018.

and coordinating the effective operation of the ocean and marine observing networks and related activities. Notable progress has been made in several areas: engaging networks to address new requirements; developing metrics to assess observing system performance; advancing the exchange of international data and metadata, encouraging system-wide standards and best practices, data management standards and integration pilot projects.
The OCG monitors and reports on progress of, and risks to, the ocean observing networks. Increasing the use of metrics throughout the ocean observing value chain allows for more robust evaluations of the system, and eventually will enable monitoring of its performance and provision of feedback into improved requirements and value. The OCG monitors and coordinates testing and assessments of ocean 


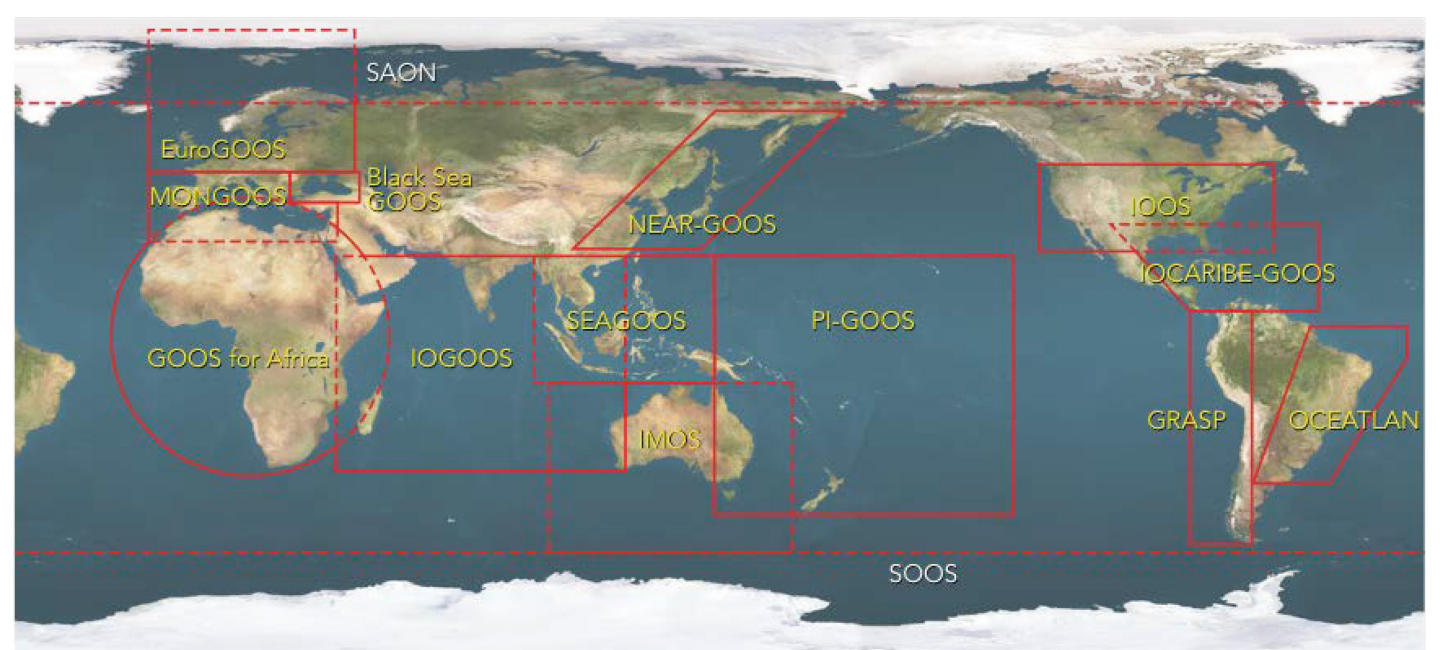

\section{GOOS Regional Alliances (GRAs)}

Black Sea GOOS

EuroGOOS

GOOS-Africa

GRASP = GOOS Regional Alliance of the SE Pacific

IOCARIBE GOOS = Wider Caribbean GOOS

IMOS = Integrated Marine Observing System (Australia)

lOGOOS = Indian Ocean GOOS

MONGOOS = Mediterranean Operational Network for GOOS
NEAR-GOOS - NE Asia Regional GOOS

OCEATLAN = Upper SW \& Tropical Pacific

PIGOOS - Pacific Islands GOOS

SEAGOOS = SE Asia GOOS

US IOOS = US Integrated Ocean Observing System

Not GRAs, but related programs

SAON = Sustained Arctic Observing Network

SOOS = Southern Ocean Observing System

FIGURE 3 | GOOS Regional Alliances (GRAs).

observing technologies as they mature and approach readiness for sustained operation, and it will support assessments that consider the mix of platforms and /or technologies to best meet requirements.

Note that the Joint WMO-IOC Collaborative Board, a high-level coordination mechanism with broader engagement of the key relevant bodies of the WMO and IOC, which will be established and, subsequently, JCOMM will phase out as a decision during the WMO Congress-18. The congress also decided to incorporate appropriate JCOMM functions and activities on observation and operational ocean forecasting systems into GOOS, with functional connections to the Commission for Observation, Infrastructure and Information Systems.

\section{GOOS Regional Alliances}

Thirteen GOOS Regional Alliances (GRAs) that have organized themselves over the past two decades covering most regions of the globe (Figure 3). GRAs enable regional cooperation in ocean observing and in some cases in ocean forecasting and services. There is great variability among the GRAs in terms of governance, scope and maturity of activity. GRA attitudes to data sharing also vary widely, from full open access in some regions to restrictions on data sharing and use in others. The regional level of governance of GOOS is therefore ripe for evolution and adaptation, a process that will need to take stock of the regional structures that organize both science and policy.

\section{GOOS Projects}

GOOS Projects inform the community on how to develop, and/or mature technologies and programs, and provide architectural patterns or best practices. These Projects are finite-term endeavors focused on common challenges that span scientific or geographic boundaries.

A key benefit to the adoption of system engineering and architecture practices is the reuse of knowledge. By taking advantage of what is known or has worked successfully in the past and making required adjustments, a Project can be a mechanism for demonstrating and/or bringing best practices into the mainstream.

The ongoing GOOS Projects also actively use the FOO processes. The Tropical Pacific Observing System 2020 (TPOS 2020, Smith et al., 2019) focused on an ocean region of high importance to global seasonal climate variability, the Deep Ocean Observing Strategy (DOOS, Levin et al., 2019) is designing and implementing an observing approach for the very under-sampled areas of the deep sea. The AtlantOS program, that arose from a similarly named European project, aims to engage a larger set of actors around the Atlantic Ocean to organize ocean observing on an ocean basin-wide level ${ }^{2}$. These projects cut across GOOS requirements, panels and observing systems, and provide insight into observing system development and best practices for future efforts (more detailed coverage of TPOS 2020 and case studies of the use of FOO are in section Case Studies).

\footnotetext{
${ }^{2}$ http://atlantos-ocean.org/
} 


\section{GOOS Partners}

In response to the requirements of a wide range of users, GOOS has developed a strategy to drive and guide implementation of a global ocean observing system. Meeting these challenges will require concerted efforts to strengthen a suite of committed and funded international partnerships.

A generalized list of partnerships that must be formed or strengthened includes:

- Organizations within the UN system, such as between IOC/UNESCO and WMO whose members increasingly recognize the importance of ocean observations for weeklyto-seasonal weather prediction, and the UN Environment Program (UNEP) with their strong mandate to monitor ecosystem health and pollution.

- Executive bodies for international conventions and agreements that require ocean information to assess progress toward their agreed objectives.

- Groups in the international marine science, management, and policy communities, such as those in climate, operational oceanography, ocean carbon, and marine ecosystems and fisheries, marine ecosystem health assessment, as well as national and regional bodies charged with evaluation of risk and management of marine systems.

- Industries and manufacturers that develop and provide instruments, platforms, and communications technologies for global sustained networks, observatories, and operational infrastructures.

- National and regional agencies responsible for funding and running ocean observing systems, many of whom are research-based, rather than operational.

- Industry sector users for whom ocean data and information are critical for sustainable, efficient and safe operations, such as shipping, tourism, offshore oil and gas, offshore wind power, seabed mining, fisheries, ocean services.

- Marine/ocean research and development sector, such as the Partnership for Observations of the Global Ocean (POGO), who often provide the innovation engine for advancing ocean observations, the proof-of-concept processes for many new observation programs, and many of the ongoing ocean observation programs.

- The data innovation and technical services sector, including the International Oceanographic Data and Information Exchange (IODE), the national ocean data centers, and other ocean data centers and data integrators.

- Non-governmental bodies that speak directly to societal concerns such as the World Wildlife Fund (WWF), Ocean Conservancy and Greenpeace.

- Finally, funders and educational partners that enable development of technical capacity in ocean observation across the globe.

\section{GOOS/FOO SUCCESSES}

Over the past decade, GOOS has shown some success in organizing and expanding the global observing system.
The FOO has provided a rigorous, standardized way for the ocean observing enterprise to be understood and advanced. It provides a framework of processes, best practices for requirements-setting based on societal needs, identification of common EOVs to be observed, technology readiness assessments (Figure 4), data sharing, product development and information delivery. As the global ocean observing system is a complex and highly connected system, addressing these information needs is an enormous challenge that has benefited from the engineering approach of the FOO.

\section{An Expanding User Base}

Over the past 5 years, GOOS has expanded to include expertise related to ocean observations across physical, chemical, biological and ecological properties. This supports not just the Intergovernmental Panel on Climate Change (IPCC) and GCOS, but also the IPBES, the Convention for Biological Diversity (CBD), the UN Environment Program, the Committee on Fisheries of the Food and Agriculture Organization (FAO), the International Council for the Exploration of the Sea (ICES), and the Regional Fisheries Management Organizations (RFMOs), among others. GOOS has been delivering relevant ocean data for various applications, often including coupling between the ocean, atmosphere and terrestrial systems. For instance, interior ocean data is increasingly used for weather forecasts, and ocean carbon fluxes are used to constrain the global carbon budget.

\section{Increased Cooperation Across Elements of the Observing Community}

GOOS has long emphasized the link between observations and end-user products in its system design and implementation. It has also encouraged GRAs and IOC member nations to make observations to support marine ecosystem health and climate issues where the link to end-users is often less obvious. This expansion of focus has encouraged the transfer of know-how among the physics, biology and biogeochemistry domains which has been a welcome development at the regional level.

GOOS has demonstrated some success in facilitating closer collaboration between the in situ and satellite observing communities, and the ocean modeling and forecasting communities. In EuroGOOS, for instance, the recent establishment of a cross-cutting coastal working group that considers the link between satellite, in situ and modeling data across scientific domains and different user groups is an impressive result of GOOS influence. Similarly, GOOS provides the ocean component of the GCOS which in turn provides a mechanism for coordination with the terrestrial, atmospheric and cryospheric observing systems.

\section{Essential Ocean Variables (EOVs)}

Much of the implementation effort to date has focused on EOVs and requirements, and it is here that we can most clearly see the demonstrated value of the FOO. The new GOOS 


\section{FOO Readiness Levels and Activities Matrix}

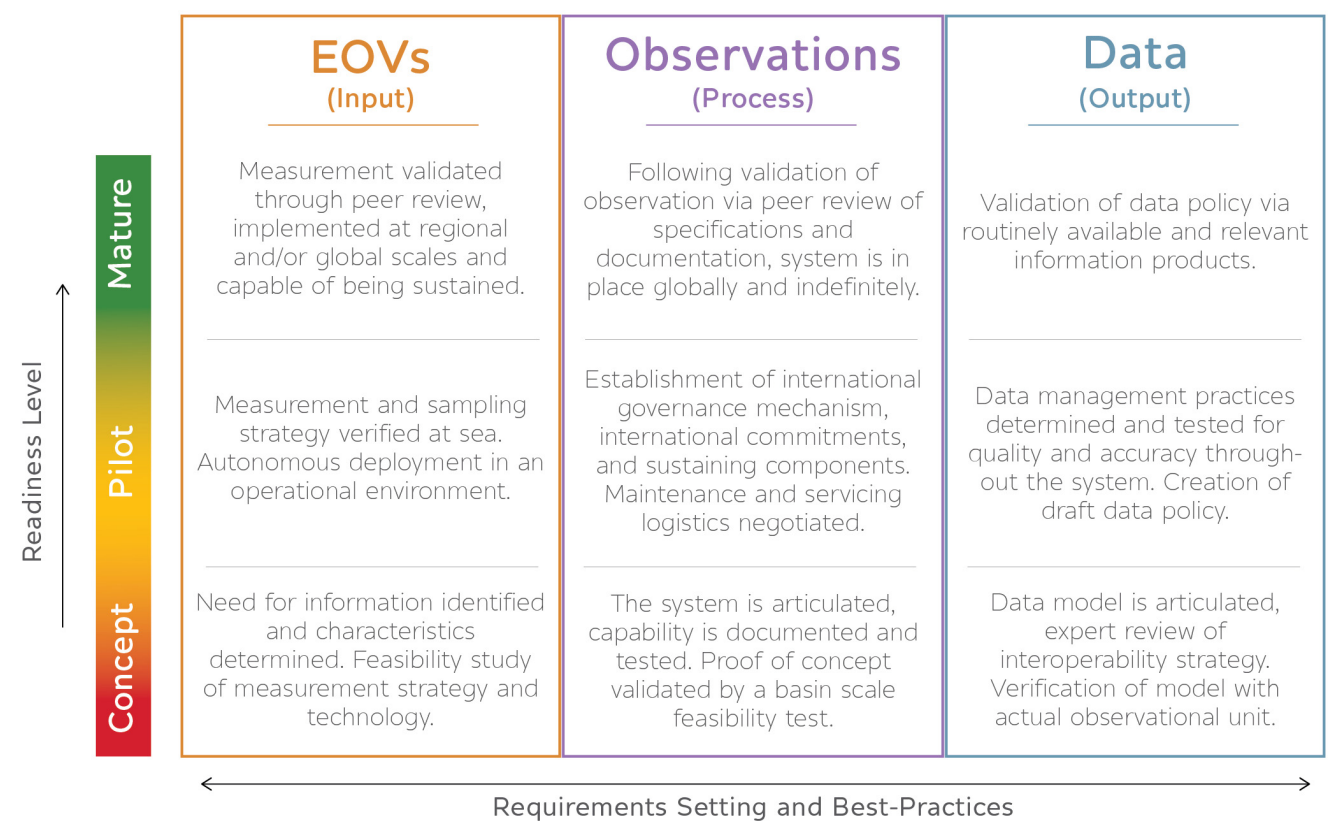

FIGURE 4 | Matrix of FOO-element attributes at increasing readiness levels.

Biology and Ecosystems Panel was able to start its requirementssetting process from the outset using FOO principles, as well as a thorough analysis using the Driver Pressure State Impact Response framework commonly used in ecosystem management (Miloslavich et al., 2018b). The panel developed a list of new, priority EOVs (Table 1), with clear societal benefit for developed and developing nations. Implementation planning is now underway.

The GOOS Biogeochemistry Panel used the FOO to evolve from its singular focus on carbon under the IOCCP to identify a new, broader set of priority EOVs (Table 2), with relevance to the United Nation's Sustainable Development Goals (SDGs). The goal is for some of these EOV observations to be established

TABLE 1 | GOOS Biology and Ecosystems Panel supported EOVs (October 2018).

\footnotetext{
Biology and ecosystem EOVs

Phytoplankton biomass and diversity

Zooplankton biomass and diversity

Fish abundance and distribution

Marine turtles, birds, mammals abundance, and distribution

Hard coral cover and composition

Seagrass cover and composition

Macroalgal canopy cover and composition

Mangrove cover and composition

Ocean Sound

Microbe biomass and diversity $\left({ }^{*}\right.$ emerging)

Benthic invertebrate abundance and distribution (*emerging)
}

as "indicators" that can be used internationally as monitors of progress toward the SDG goals, and those of related intergovernmental conventions.

The FOO has also influenced priorities under the most recent review of GCOS, enabling better linkages across ocean physics, biogeochemistry, and biology and ecosystems. It has enabled the GOOS Physics Panel, whose EOVs are shown in Table 3, to begin responding to requirements in continental shelf and coastal systems through a focus on boundary currents.

A number of the EOVs identified by the three panels are clearly interdisciplinary, such as ocean sound, which is physical measurement but is often measured to assess its effects on ocean mammals and fish. Lead responsibility for these cross-disciplinary EOVs has been assigned to the Panel which is deemed most in need of the data. The EOVs identified by the three panels are continuously evaluated and

TABLE 2 | GOOS Biogeochemistry Panel supported EOVs (October 2018).

Biogechemistry EOVs
Oxygen
Nutrients
Inorganic carbon
Transient tracers
Particulate matter
Nitrous oxide
Stable carbon isotopes
Dissolved organic carbon
Ocean color

\section{Biogechemistry EOVs}

Oxygen

Inorganic carbon

Transient tracers

Particulate matter

Nitrous oxide

Dissolved organic carbon

Ocean color 
TABLE 3 | GOOS Physics Panel supported EOVs (October 2018).

\section{Physics EOVs \\ Sea state \\ Ocean surface stress \\ Sea ice \\ Sea surface height \\ Sea surface temperature \\ Subsurface temperature \\ Surface currents \\ Subsurface currents \\ Sea surface salinity \\ Subsurface salinity \\ Ocean surface heat flux}

evolved by interaction with their scientific and operational user communities.

\section{Best Practices}

The use of best practices fostered by the FOO has supported many positive outcomes for the ocean observing system (Pearlman et al., 2019):

- Identified (minimal) system attributes for multiple system components, such as sensor performance, observing, data models, data quality, and data flow

- Encouraged more complete capture of metadata, important for data quality

- Enabled more rapid capacity development through sharing of knowledge

- Encouraged more contributions of usable data and better data quality

- Enabled system-wide integration across networks around EOVs.

\section{User Feedback}

Use of the FOO has also addressed the need to involve the end user in assessing and achieving the full societal benefit of sustained ocean observing by:

- Encouraging the practice of establishing user-driven requirements around EOVs

- Requiring assessment and feedback of the effectiveness of the observing system in addressing these requirements/needs

- Encouraging and assessing synthesis-based products based on EOV observations

- Recognizing and advancing these synthesized EOV Products (e.g., Sea Surface Temperature, ocean currents, global sea level rise estimates, wave field) as a critical bridge between raw observations and user-driven needs.

\section{USING THE FRAMEWORK}

As GOOS responds to new requirements for measuring additional EOVs in coastal and open ocean environments, it must also include new observing system elements and networks. In many instances, GRAs are already operating observing networks that are potentially fit for these purposes. Examples include high frequency radar, ocean glider, and animal tracking networks. Here we have seen the networks and GRAs, and large Projects come together as ocean observing communities to propose expansion of GOOS in line with the FOO (while not a GOOS Project the Southern Ocean Observing System generated its own version of ecosystem EOVs or eEOVs). The need to address requirements, measure priority EOVs, and provide data and information products is accepted by these communities. This indicates that the usefulness of guidance provided by the FOO is also being recognized by many from the "bottom up."

Argo provides a good example of how the FOO can be used to evolve an existing observing system element in response to new requirements. The Argo profiling float network, which is at a mature level of readiness for its core variables and spatial coverage, is now challenged to mature technologies and data delivery for floats measuring additional EOVs. Biogeochemical and bio-optical Argo floats (Bio-Argo) are now at a pilot level of readiness and are being trialed in the Southern Ocean and other locations. Deep Argo is at a proof-of-concept level of readiness, also within FOO guidelines, with several experiments underway.

\section{Case Studies}

Several case studies presented in the text boxes below address both successes and challenges in real-world application of the FOO guidelines.

\section{A national case study - the Integrated Marine Observing System (IMOS)}

The Integrated Marine Observing System (IMOS) is a national collaborative research infrastructure funded by the Australian Government, doing systematic and sustained observing of Australia's vast ocean territory, and making all its data openly accessible for science, research, and other uses. IMOS is integrated across scales (open ocean, continental shelf, and coast), and across disciplines (physics, biogeochemistry, and biology and ecosystems). Established in 2007, it has been expanded, consolidated, and sustained over the past decade.

This period overlapped with development and dissemination of the FOO, and IMOS has used the common language and system design principles of the FOO in numerous ways.

IMOS requirements were initially set through national science planning, subject to international peer review. Within a socio-economic context, major research themes and science questions were identified (requirements), leading to the prioritization of variables to be measured at relevant time and space scales (EOVs), along with platforms and sensors to be utilized (observing system elements). Direct investment in information management infrastructure was a design feature from the outset.

IMOS has also used the FOO concept of readiness to assess technology investments over time. Investing mostly in mature technologies to ensure delivery of quality data for its missions, IMOS has also run pilot projects of some newer technologies, maturing them if successful, or discontinuing them if not.

Now funded to 2023, with strong prospects out to 2029, IMOS is looking to strengthen its use of FOO elements that have served it well. Based on the 
expectations of Australian Government, requirements will be more clearly defined based on social, environmental and economic drivers. The strategy is to move from use and impact being something that emerges from what we do, to something that is explicitly planned for and measured. Direct investment will also be made in new technology assessment, with more rigorous selection and evaluation of pilot projects. There will also be emphasis on areas where the FOO has been less influential to date: increasing effectiveness and efficiency, greater integration across EOVs, and more investment in value-added information products.

A regional case study - the European Ocean Observing System (EOOS)

European stakeholders in ocean observation are working together in the European Ocean Observing System (EOOS) under the guidance of EuroGOOS and the European Marine Board. Stakeholder events and consultations have been held to gather perspectives on how the current system can be broadened to include marine ecosystem health, climate observations and applications, as well as the traditional data collection that supports real time oceanographic services for the user community. EOOS aims to establish a mechanism for a wide range of users to formulate and convey their needs to ocean observation system implementers, where they can be transformed into data requirements and the most appropriate measurement strategies can be identified. EOOS will also provide a mechanism to track and assess the implementation of solutions to meet user needs.

The requirements feedback loop advocated in the FOO has provided a globally-adopted context for this cycle of user requirements, implementation and tracking of observing system implementation for EOOS. In the future EOOS will look to a more mature FOO to help address the effectiveness of various mechanisms for gathering user feedback to inform future advances in ocean observing system design.

\section{A basin-scale case study - TPOS 2020 \\ The TPOS 2020 Project is evaluating all elements that contribute to ocean observing in this area, based on a modern understanding of the science and the capabilities of new sensing technologies, and recommending a redesign that will deliver enhanced effectiveness for all stakeholders, including operational climate prediction systems (Cravatte et al., 2016; Smith et al., 2019). In the context of FOO it is a regional Project, owned by regional stakeholders, but otherwise well aligned with the basic concepts of the FOO. The First Report of TPOS 2020 is structured according to the FOO in the following ways:}

- User requirements are expressed in terms of EOVs and characteristic scales and quality

- Generic, platform-agnostic recommendations are high-level responses to those requirements, which manifest as requirements on the various platforms and networks

- Possible platform and network solutions take account of the complementary capabilities of different approaches.

Differentiating these distinct levels of requirements was a constant source of debate, with the ever-present temptation to immediately focus on the technology solutions. It is critical these steps are considered independently to avoid conflicts of interest. Research and societal needs must be considered together. The First Report further refined the meaning of "essential" and differentiated between experimental and sustained measurements. Process experiments and pilot studies were managed somewhat differently from FOO, but their important role was fully recognized (Smith et al., 2019).

TPOS 2020 is moving toward a regional governance model involving key stakeholders and partners; again, this differs somewhat from FOO which emphasizes global aspects. This does require further elaboration - FOO is a top-down construct but allows for bottom-up development and direction.

\section{GOOS CHALLENGES}

Requirements for the ocean observing system are expanding. GOOS faces many challenges to its further success in addressing the entire value chain (Figure 5). These range from an increased urgency to articulate EOV requirements for an ever more complex and demanding user community, to the engagement with industry. Technologies need to mature to meet expanding needs along with the markets for these technologies such that they are both reliable and affordable. In addition, better systems for standardizing instruments, including quality assurance and telecommunications methodologies, and for encouraging a stable but diverse community of technology providers, is needed. There is also a need for engagement of data and user communities to ensure the uptake and expanded utility of data and information products. In addition, a global and inclusive governance architecture is needed to enable direction setting and coordination of ocean observing (see section Improving Governance of the Ocean Observing System: Revolution OR Evolution?).

\section{New Technology}

While observing technology (including sensor systems, platforms, data transmission, archival systems, data analysis software, and user product) evolves rapidly, the sustained observing system must balance responsiveness and continuity. It is challenging to determine where and why investment should be made for maximum utility. This applies both to new sensors, such as those for measuring biogeochemical properties, and to more well-established systems such as instruments for measuring sea level. It is a significant challenge to balance the incorporation of new technologies while sustaining the appropriate legacy components of the system, while ensuring the necessary calibration, verification and integration of all data sets, models, and end-user products, (see for instance the GCOS monitoring principles ${ }^{3}$ ).

\section{Gaps in the Observing System}

As the system grows to serve a broader suite of users across operational services and marine ecosystem health, encompassing both open ocean and coastal applications, the complexity of the environment is increasing. There are profound gaps in ocean observing coverage. For instance, the ocean observing capacity to monitor human impacts on the global ocean and climate must be engaged and improved.

\section{Best Practices}

GOOS's observations come from many heterogeneous observing elements funded by different nations and agencies and run by different groups, which can all benefit from increased sharing of best practices and integration.

Some observing networks, such as Argo or HF Radar, that focus on particular technologies are quite effective at developing and sharing best practices. Given the wide range of observing systems and end-users around the globe, however, we have

\footnotetext{
${ }^{3} \mathrm{https} / /$ gcos.wmo.int/en/essential-climate-variables/gcos-monitoring-principles
} 


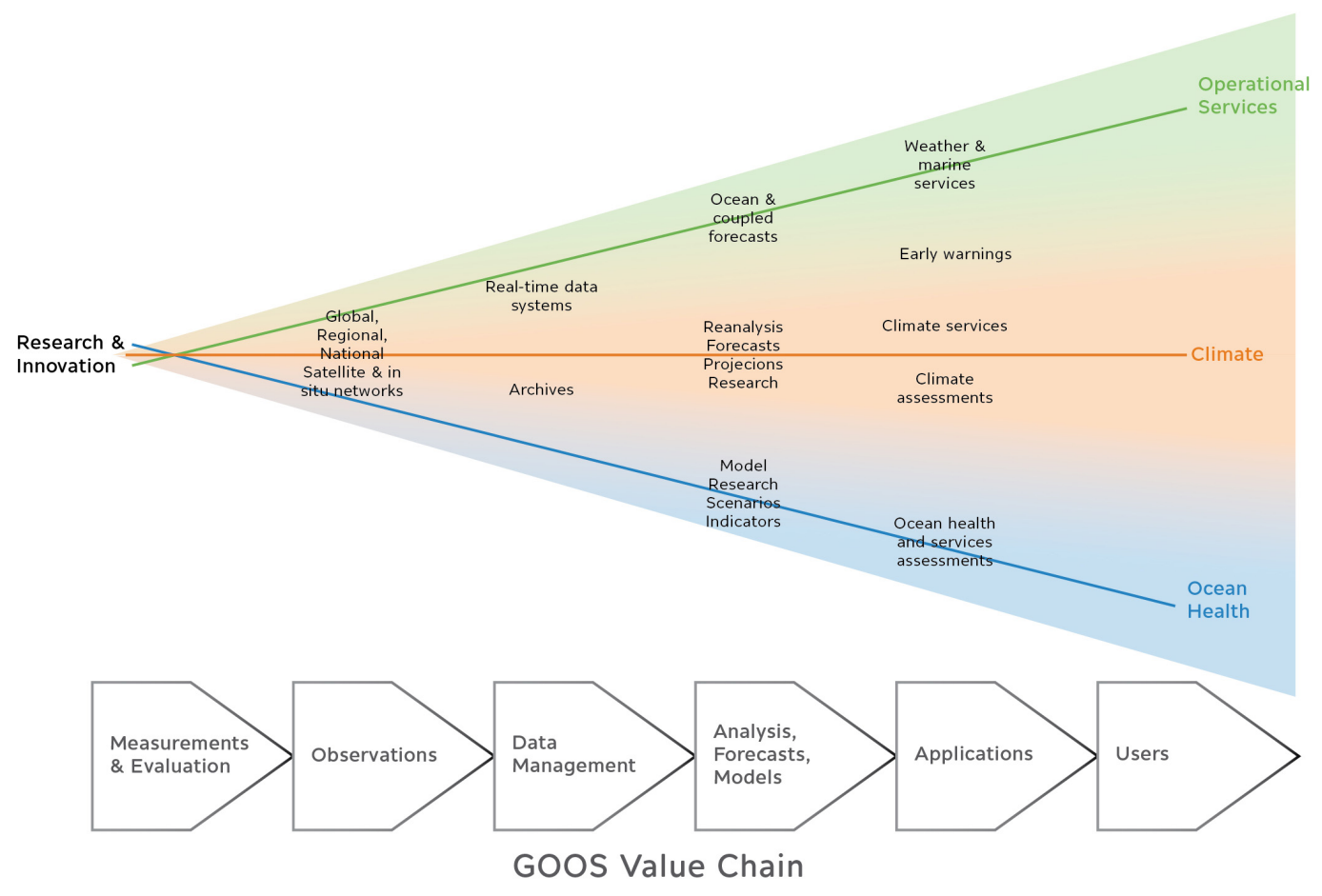

FIGURE 5 | GOOS value chain and associated activities and outcomes.

learned that relying on informal processes to share best practices is inadequate. There is a critical need to increase emphasis on identifying, sharing and following lessons learned and best practices across the GOOS enterprise. Important aspects of this work are being addressed by the Best Practices Working Group (Pearlman et al., 2019). Once these best practices are better socialized, it is expected user group communities will form to mature these practices and create a better understanding of the need for more formal interfaces and associated governance or institutional support.

\section{Integration and Feedback}

Given the evolution of user needs, the observing system and protocols for the analysis of observations, it is important that there be regular periodic reviews of the value chain to ensure that it continues to meet both scientific and societal needs. Currently feedback from end-users to the observing system is largely ad hoc. Development of a robust assessment component for GOOS is needed, with a wide range of questions addressed: How well are requirements being met? Do the requirements need revising? Is the mix of observing elements optimal? Are data quality and attributes acceptable? Do the products contain useful information? How well are user needs being met? The FOO identifies the need for regular cycles of evaluation to ensure the data products meet designated requirements and to ensure the information generated is having impact on the societal issues the observing system is designed to address. However, there is a fundamental lack of connection across the value chain from observations to end use, and in the ability to ensure fit-for-purpose delivery of information. Feedback and assessments should also track progress over time. Metrics for measuring GOOS system performance are under discussion and must be developed.

\section{Funding the Observing System}

Although we have grown the capability and associated funding for the ocean observing system (all elements) enormously over the last 25 years, particularly from satellites and modeling, the current findings of the in-situ observing system rely on a mixed funding model, with proposal-driven sources continuing to provide the bulk of the capability. New requirements, such as those from ocean health and sustainable development of the marine environment remain largely unfunded. Many of the ocean observing networks are largely dependent on short-term research projects. Nations have traditionally funded observing networks in their own waters to support marine transportation and public safety needs. Expansion of the scope and requirements into ocean health and environmental concerns has greatly increased the demand for observations without a commensurate increase in funding, which is putting enormous pressure on the system. Building the expanded system needed will require more cooperation and more funding across the ocean research, operations and policy communities worldwide. Ocean observing must be moved further up the political agenda internationally, and there is a fundamental need for long-term funding mechanisms to support ocean observing. Except for weather forecast systems, there is no collective knowledge base for assessing the value of ocean data products and services. 


\section{Capacity Development}

Building an operational system that is truly global requires expanding participation to include a far broader representation of developing and less-resourced countries. Significant global efforts to support capacity-building have been sponsored through a variety of organizations including the IOC, but the truth is these have not been sufficiently effective. To succeed, capacity development strategy must be sustained, and stronger partnerships, new funding models, innovative technologies, and new training approaches will be required (Bax et al., 2018; Miloslavich et al., 2018a). The goal is to have more countries actively participating in GOOS observing and benefiting from its information products.

\section{Engaging the Private Sector and New Partners}

There is a growing need to address the expanding role played by volunteer and chartered vessels hired to conduct observational efforts. In order to deliver ocean information to the end-user it is important to engage partners through the whole value chain. This includes a stronger engagement with private sector partners, both as a delivery of observations, or as users of ocean information. For example, in 2017, 27\% of the total CMEMS (Copernicus Marine Environmental Monitoring Service; a large operational GOOS user) download volume (around 45 Terabyte) was for private/commercial applications. On the observation side, private sector vessels (volunteer, charter) are widely used (e.g., volunteer observing vessels; maintenance of the tropical moored buoy array; tsunami moorings). As noted above, GOOS needs to better engage instrument and communication system manufacturers in setting and providing standardized platform operations and in evolving the cadre of data collection providers from the private sector.

\section{Data Sharing}

The ocean data system architecture is incomplete and fragmented, and the revolution of free and open data sharing achieved for most open-ocean physical variables is not universally inclusive of the biogeochemical and biological variables, or to certain other ocean areas. GOOS is a strong supporter of the principle "measure once/use many times." As an IOC program, GOOS adheres to the IOC oceanographic data exchange policy (Resolution IOC-XXII-6, 2003), which stipulates that Member States shall provide timely, free and unrestricted access to all data, associated metadata and products generated under the auspices of IOC programs ${ }^{4}$.

On 21 March 2018, Nature published the results of a large survey on the practical challenges of scientific data sharing. It showed that $76 \%$ of respondents highly rated the importance of data being discoverable, but the main challenge to data sharing is organizing data in a presentable and useful way (46\%), followed by confusion around copyright (37\%) and not knowing where to share data (33\%). This confirms that there is still a strong need

${ }^{4}$ www.iode.org/policy

${ }^{5} \mathrm{http} / / /$ go.nature.com/ResearchDataWhitepaper to improve capacity in data management, promote best practices in global common data standards, data exchange protocols, and expert-controlled vocabularies to ensure interoperability between datasets.

The FAIR (Findable, Accessible, Interoperable, and Reusable) Guiding Principles (Wilkinson et al., 2016; Tanhua et al., 2019) now enjoy broad recognition through the data community. Several oceanographic organizations/projects, such as the AtlantOS Blueprint - Data flow (de Young et al., 2019), are already embracing the FAIR Principles alongside the consideration of EOVs and requirements, so it makes sense to bring them into GOOS.

\section{FOO COMMUNITY REVIEW}

A community-wide review of the FOO's usefulness was launched in August 2017. Twenty-one extensive interviews were conducted with representatives from federal agencies, research institution, academia, and the private sector. These discussions focused on three broad categories: technology and implementation, data and analysis, and management and governance.

This effort resulted in several key findings that will guide changes to use and implementation of the FOO. Recommended changes so far are that there should be an increased emphasis on the multi-scale (coastal, open-ocean, local, regional, national, global) aspects of the observing system. Also, there must be improvements in assessment methods to clarify the path to maturity across the system.

A brief summary of early results from the FOO Community Review:

- The FOO has been helpful in the establishment of EOVs, however, the observing community could benefit from an ongoing review of the EOV setting process and its outcomes.

- While alignment with FOO did facilitate the dialog around what should be measured, it was not as useful in negotiations of what sensors should be deployed on observing platforms, or in the design or redesign of observing networks or arrays.

- There is a greater need for interaction among data managers and integrators within the system. The implementation and data management teams are often overlooked in conversations when calling for enhanced relationships with users, and the needs of these users are often not sufficiently funded or managed in a sustained manner.

- There is a need for greater awareness of the role of GOOS and other groups functioning in the international coordination arena.

- Improved understanding and strengthened partnerships can assist the international community in addressing the entire value chain of the ocean observation system.

- In addition to the expanded emphasis on building an observation and data and information infrastructure that is based on the scientific understanding generated by the EOV setting process, practitioners are also challenged to 
develop the more direct or concerted relationships required to develop the system's feedback loops further addressing science and societal needs.

\section{THE WAY AHEAD}

GOOS is looking forward to the coming decade by assessing its unique role in ocean observing to date, reviewing remaining challenges, and considering how it can best improve its contributions in the future. The GOOS 2030 vision (IOC, 2019) was published in April 2019 (pending approval of IOC General Assembly); the mission, goals, and strategic objectives are presented in this paper. Responses before and during the OceanObs'19 Conference in September 2019 (Honolulu, United States) will inform and refine how GOOS will implement the strategy during the next decade.

\section{The GoOS Vision}

\section{A Truly Integrated Global Ocean Observing System That Delivers the Essential Information Needed for Our Sustainable Development, Safety, Wellbeing and Prosperity}

Compared with GOOS at its creation in 1991, GOOS now has a very broad, societally-driven perspective, responding as required to all relevant SDGs and to the many other users of, and stakeholders in, the GOOS. This in turn mandates GOOS to provide a systematic, integrated and effective response to this complex set of information requirements.

\section{The GOOS Mission}

To Lead the Ocean Observing Community and Create the Partnerships to Grow an Integrated, Responsive, and Sustained Observing System

A fully implemented global ocean observing system will provide the critical ocean information needed to address climate change, generate forecasts, and protect ocean health. By 2030, GOOS will engage a greatly expanded level of partnership and participation from more countries, other observing organizations, and users of data and products.

\section{GOOS Goals and Strategic Objectives}

GOOS will work with its partners over the next decade to address ocean information issues and achieve its vision through 11 Strategic Objectives, grouped under Three Overarching Goals shown in Figure 6.

- Goal 1: Deepening Engagement and Impact

Deepen engagement and partnership from observations to end users to advance the use and impact of the observations and demonstrate its benefits

(1) Strengthen partnerships to improve delivery of forecasts, services, and scientific assessments.

(2) Build advocacy and visibility with stakeholders through communicating with key users and national funders.

(3) Regularly evaluate system impact to assess fit for purpose.
(4) Strengthen knowledge and exchange around services and products, to boost local uptake.

- Goal 2: Supporting Integration and Delivery

Deliver an integrated, "fit for purpose" observing system built on the systems approach outlined in the Framework for Ocean Observing

(5) Provide authoritative guidance on integrated observing system design, synthesizing across evolving requirements and identifying gaps.

(6) Sustain, strengthen and expand observing system implementation through GOOS and partner communities, promoting standards and best practice, and developing metrics to measure success.

(7) Ensure GOOS ocean observing data and information are findable, accessible, interoperable, and reusable, with appropriate quality and latency.

- Goal 3: Building for the Future

Building for the future through innovation, capacity development, and evolving good governance

(8) Support innovation in observing technologies and networks.

(9) Develop capacity to ensure a broader range of beneficial stakeholder participation.

(10) Extend systematic observations to understand human impacts on the ocean.

(11) Champion effective governance for global in situ and satellite observing, together with partners and stakeholders.

\section{IMPROVING GOVERNANCE OF THE OCEAN OBSERVING SYSTEM: REVOLUTION OR EVOLUTION?}

The world at large is recognizing the magnitude of the ocean's impact on global, regional and local lives and livelihoods. These include the ocean's impacts on regulating climate and the tendency toward local extreme storm and flooding events; global sea level rise; and the growing problems of ocean warming, acidification, plastics and other forms of pollution. Many nations are calling for improved public safety forecasts and warnings; international conventions and regional agreements are calling for more ocean observations to address their various concerns; and ocean scientists urgently require more ocean observations to support these many needs. At the same time, there is a growing "blue economy" with many innovations in marine transportation, search/salvage, food production, underwater mining, recreational boating, and many other maritime industries. The requirements for increased ocean observations to address all of these issues, and to provide products to support them is growing in number.

There is a wide and growing range of participants worldwide in ocean observing with different scopes, aims and ambitions and different geographical, thematic and technical foci. Significant 


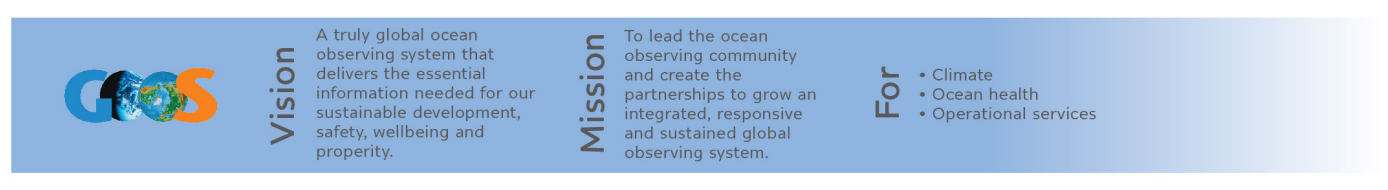

Strategic Goals \& Objectives

\begin{tabular}{|c|c|c|c|c|c|c|c|}
\hline 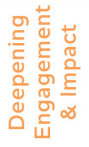 & 1 & $\begin{array}{l}\text { Strengthen partnerships, } \\
\text { to improve delivery of } \\
\text { forecasts, services, and } \\
\text { scientific assessments. }\end{array}$ & 2 & $\begin{array}{l}\text { Build advocacy and } \\
\text { visibility with stakehold- } \\
\text { ers through communicat- } \\
\text { ing with key users and } \\
\text { national funders. }\end{array}$ & 3 & $\begin{array}{l}\text { Regularly evaluate } \\
\text { system impact to } \\
\text { assess fit for } \\
\text { purpose. }\end{array}$ & $\begin{array}{l}\text { Strengthen knowledge and } \\
\text { exchange around services and } \\
\text { products, to boost local } \\
\text { uptake. }\end{array}$ \\
\hline
\end{tabular}

\begin{tabular}{|c|c|c|c|c|c|c|}
\hline 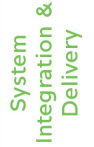 & 5 & $\begin{array}{l}\text { Provide authoritative } \\
\text { guidance on integrated } \\
\text { observing system design, } \\
\text { synthesizing across } \\
\text { evolving requirements } \\
\text { and indentifying gaps. }\end{array}$ & 6 & $\begin{array}{l}\text { Sustain, strengthen and expand } \\
\text { observing system implementa- } \\
\text { tion through GOOS and partner } \\
\text { communities, promoting } \\
\text { standards and best practice, and } \\
\text { developing metrics to measure } \\
\text { success. }\end{array}$ & 7 & $\begin{array}{l}\text { Ensure GOOS ocean } \\
\text { observing data and } \\
\text { information are findable, } \\
\text { accessible, interoperable, } \\
\text { and reusable, with } \\
\text { appropriate quality and } \\
\text { latency. }\end{array}$ \\
\hline
\end{tabular}

\begin{tabular}{|c|c|c|c|c|c|c|c|c|}
\hline 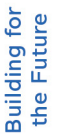 & 8 & $\begin{array}{l}\text { Support innovation in } \\
\text { observing technolo- } \\
\text { gies and networks. }\end{array}$ & 9 & $\begin{array}{l}\text { Develop capacity to ensure } \\
\text { a broader range of } \\
\text { beneficial stakeholder } \\
\text { participation. }\end{array}$ & 10 & $\begin{array}{l}\text { Extend systematic } \\
\text { observations to understand } \\
\text { human impacts on the } \\
\text { ocean. }\end{array}$ & 11 & $\begin{array}{l}\text { Champion effective } \\
\text { governance for global in } \\
\text { situ and satellite observing, } \\
\text { together with partners and } \\
\text { stakeholders. }\end{array}$ \\
\hline
\end{tabular}

FIGURE 6 | GOOS 2030 Strategy; vision and mission statements with strategic goals and correlating objectives.

expansion of new observing efforts has recently increased the community's intellectual and operational capability, which is a great outcome. However, there is unbridled growth in the number of groups taking on responsibilities without appropriate coordination: the system has ineffective systemlevel management, lack of planning coordination across the system, and sub-optimal financial and management support levels for many of the efforts. This lack of awareness of, and/or coordination with, already existing observing systems in some areas has resulted in less positive outcomes, including duplication of observing efforts, use of less-than-optimal observing technology, and limitations in data standards and data sharing. The rapidly increasing requirements, the growing landscape of actors and activities in ocean observing, and the constrained resources, require that some form of improved ocean observing governance evolve that can effectively and efficiently address the growing needs of the many stakeholders.

Most of the funding for ocean observation infrastructure continues to come from national governmental funding sources, so the strongest level of governance around planning, commitments and implementation continues to be at the national level. Improved governance must demonstrate to the national players how engagement across regional and global levels can bring advantages, for example from cooperation and coordination and leveraging the best practices of others. Furthermore, engagement at the global level will give all participants in ocean observing more access and input to the development and implementation of intergovernmental conventions that require ocean observations.

Improvement of the governance system must focus foremost on finding common requirements and building strong partnerships across the expanding observing system.
It is necessary to define roles and responsibilities and agree on goals and strategies including processes for setting system requirements, assessing technology choices, setting standards for data management and sharing, coordinating the suite of public products, and cooperating in global capacity development on all levels.

It is important to understand where commitments take place for the observing system, and how governance can be more effective and efficient internally, while at the same time recognizing and working more closely with other partners to build the case for additional investment in the observing system.

\section{Dimensions of Ocean Observing Governance Structures Today}

This diversity, energy and activity in the global ocean observing community can be seen both as a strength and a weakness of the current ocean observing system. The global ocean observing community is multi-faceted, loosely organized, and growing more so every year. We operate now with an historical accretion of organizations and networks working at different scales and focused on different parts of the value chain from observations to end users.

Structurally the community can be looked at as being aligned around three dimensions:

\section{- A first dimension is that of platform-based observing.}

A core component of the observing system has long been the observing networks organized around particular observing platforms. Good examples are profiling floats (Argo), moored time series (OceanSites), large scale hydrography (Global Ocean Ship-Based Hydrographic Investigations Program). These networks operate under well-defined criteria and shared best 
practices. They have their own governance systems, are global in ambition, promote free and open data sharing and aspire to be sustained. These networks tend to be focused on specific scientific and/or societal user needs but are not well integrated with other observing systems even when in the same area.

\section{- A second dimension is that of ocean observing requirement themes.}

Good examples are the newly developed Global Ocean Acidification Observation Network (GOA-ON) and the Group on Earth Observations Biodiversity Observation Networks (GEO BON) and the Deep Ocean Observing Strategy (DOOS) Project. Thematic based collaborations allow for broad, and as appropriate, multi-disciplinary engagement across geographic areas. Currently there are efforts underway to more systematically align these thematic networks within the broader GOOS structure and encourage wider use of the FOO principles and processes.

- The third dimension is that of scale.

Governance challenge varies as we move from national and regional scales, to basin and global scales. The bulk of the funding for ocean observations comes from the national level where the strongest governance also exists (for example, accountability for public funds), although governance arrangements differ from nation to nation, and there is no standard or organized coordination across nations. The nations mostly oversee their own local observing networks, although in some nations there are so many that they are not really well coordinated, and in other nations, outside organizations sometimes take the lead without coordinating strongly with national agencies.

The regional level has both geopolitical and natural ocean drivers and motivation for cooperation, like regional current systems, pollution, fisheries, and other issues of resource management and protection. Yet today there is no single governance solution for regional efforts, not just for ocean observations, but also for the broader issues of transboundary problems and regional politics. The regional scale of governance for both science and policy is ripe for improvement.

A recent positive development has been the emergence of coordination at the scale of complete ocean basins. Good examples include the Southern Ocean Observing System (SOOS), AtlantOS for the Atlantic, the Indian Ocean Observing System and TPOS2020 focusing on the tropical Pacific. The basin-scale focus provides a new and effective vehicle for collaboration on ocean observation requirements, observing strategies, data sharing, capacity building, and resourcing, though still with some of the challenges identified for the regional scale. The European Commission has pursued this scale of cooperation for ocean science with the Galway Statement (2013) and the Beléem Statement (2017), covering North and South Atlantic Ocean research and observing cooperation, respectively.

GOOS governance focuses on the global scale, but also embraces elements of regional and basin-scale approaches.

\section{Voluntary Contributions}

Perhaps most importantly, there is currently no mechanism in place to assess the effectiveness of the total contribution of ocean observations and data streams from the variety of networks and components toward the goals of the scientific and societal benefit areas recognized as the overarching purpose for the observing system. This speaks to both one of the greatest achievements of the observing system in the previous decade - the more widespread adoption of open data policies but also to one of its greatest challenges for the next decade: the lack of an appropriate governance structure for the vast resources of scientists, technology developers, and data experts that involved. The governance is under tremendous pressure to both respond as well as lead to resolve the issues related to associated requirements development and communications gaps.

The current governance system is loosely coordinated based on voluntary commitments with little of the rule and control characteristics usually associated with more formalized governance structures. The variety of differently focused observing systems makes it challenging to find a governance model that works; the current model is clearly not adequate to accommodate, oversee, guide, or support all systems. Additionally, governance of ocean observing is not well supported; both in terms of investment and commitment. One possible reason for this is the inherently unclear and complex structures, roles and responsibilities of the current governance arrangements.

\section{Attributes and Objectives of a Good Governance System}

All indications are that the diversity of expertise, interests, and support for the fragmented global ocean observing community will continue to expand in the coming decade. The "next step" for high-level governance of the global ocean observing system must be attractive in order to involve more representatives from the community, including some who are currently working in isolation. The FOO principles will be a valuable resource toward establishing guidelines, standards and procedures for moving forward.

In a recent assessment of over 100 international agreements comprising the global ocean governance architecture for fisheries, pollution, biodiversity and climate change, Mahon et al. (2014) found two emerging network structures. The first were "global-regional, issue-based networks" building from the siloed global agreements touching fisheries, pollution, biodiversity and climate change, which they suggested should be better integrated. At the regional level, they found 16 crosscutting regional clusters of networks, where regional agreements for several issues coincide spatially. They suggested these clusters provide the opportunity for integration, focusing broadly on ecosystem-based management of the ocean, and improving regional implementation of global agreements. Sustained ocean observations are a necessary input for all of these initiatives, as is scientific input for setting requirements and policy and in monitoring outcomes, but Mahon et al. (2014) found that many of these mechanisms to incorporate science into policy 
were weak. This study makes clear the requirements and the opportunities for strengthened governance at both the global and regional levels.

Based on experience with GOOS and similar systems, and on initial stakeholder consultation, we propose the following principles for an observing system governance structure:

- Responsiveness: Governance must respond to the needs of stakeholders and participants, from local, regional to global, across all relevant sectors, and include governmental and non-governmental aspects.

- Purposeful: Governance must demonstrate purposefulness for, and on behalf of, the community.

- Clear objectives: Good governance relies on clear and relevant objectives and strategy.

- Transparency: Transparency and openness must be a priority, to ensure broad and public access to and benefit from the system. While some private (closed) networks may be warranted on the grounds of security or because they address a narrow target audience, in general information should be public and governance arranged accordingly.

- Efficiency and Effectiveness: Governance must ensure that maximum value is derived from invested resources and must have sufficient flexibility and nimbleness to ensure that both decisions and/or guidance are provided in a timely way.

- Adaptive: Governance must support innovation and an openness to change, in order to ensure that benefits accrue for new solutions and improved best practices.

- Sustainability: Governance must have a long-term orientation, taking account of the broad range of existing and likely future drivers, and the need for dependability and robustness.

- Authoritative: The individuals and teams contributing to governance must have the appropriate capability, skills, and respect of the community to act on their behalf.

- Performance and accountability: The governance processes must include monitoring and feedback to measures of success and performance.

An additional principle when dealing with multiple levels of governance is that a central authority should have a subsidiary function, performing only those tasks which cannot be performed at a more local level. This subsidiarity principle establishes a link of co-responsibility among different levels of governance. The central idea is that local governance will be the most responsive to local needs, increasing quality and effectiveness and managing risk at the appropriate level (Jachtenfuchs and Krisch, 2016).

The above principles are intended to provide a firm foundation for building a new governance system and are not prescriptive. If after further consultation with stakeholders these principles are judged to capture the needed objectives and attributes, then the details can follow.

It is important to recognize the nesting from national to regional or basin-scale to global efforts; the needs and contributions of each level; and how a governance system must work with and help to coordinate the efforts of all of these levels to achieve the best system of systems for all users. We need to invest in projects to test and demonstrate the linking of the various governance levels.

\section{Scenarios for Improved Ocean Observing Governance}

The ultimate objective is a better-structured, efficient system-ofsystems, or enterprise with clear roles and responsibilities and a sense of ownership among all members in the overall system, where all individual parts work in concert, with observations, standards, data sharing and data product needs met in the most efficient and cost-effective ways.

How do we get there? We offer several scenarios for improving governance of the overall ocean observing community.

\section{Starting Over - A Revolution}

If we could start over and build the ideal governance structure from scratch, what could it look like?

There would be a strong, single international organization with a clear mandate and adequate funding to direct, coordinate, integrate, monitor and assess ocean observations, data and products worldwide, and to provide and coordinate robust capacity building for nations in need of it. It would direct and oversee expanded use of the FOO, including requirement setting organized around EOVs, observing technology and design readiness assessments, increasing user feedback, and assessing the adequacy of the system in meeting societal benefits. It would establish and support strong channels for two-way communications and mechanisms for the input of ideas and leadership from national and regional levels.

This organization would adhere to all the principles, objectives, and attributes of governance outlined above. All other intergovernmental organizations needing ocean information would be incentivized to coordinate their needs and efforts with the lead organization.

Every nation with an ocean coastline would have an "ocean ministry," responsible for coordination of ocean science and observations. In nations with multiple ocean agencies, one would be clearly designated as the lead for ocean observations. These national ocean ministries would coordinate their ocean observing efforts with the lead international organization. Regional observing efforts would have clear and shared common governance arrangements and would be required to coordinate with and take direction from the lead international organization. Both national and regional observing efforts would work closely together by participating in established mechanisms for their input and leadership of various aspects of the global effort. All the geographical scales of ocean observing would be linked, both "upward" and "downward" to assure engagement, ownership, consistency and cost-effectiveness of the overall system.

Clearly, starting over is not a realistic option. There is no identified mechanism to make that level of change achievable in a system with so many players and, even if possible, it would cause too much disruption to important ongoing and emerging observing efforts. Perhaps this look at an idealized model will inform the goals and attributes of the evolutionary approaches outlined below. 


\section{Top-Down Model}

A top-down governance system led from some part of the UN system has some strengths: it is rooted in Member State governments, it is consensual and inclusive, and conditioned to treat capacity development as a priority to bring the community of nations up to a common level of development. That leads to some of its disadvantages: a consensual drive can lead to lowest-common denominator responses to innovation.

A good example of a top-down model is the rather strongly regulated framework around meteorological observations, recognized many decades ago as vital to public safety (weather and storm forecasts), business interests (agriculture, aviation forecasts), and military needs. Governed by the WMO under the WMO convention, members have a strong say in formulating regulations, but once promulgated the WMO regulations are largely complied with by most nations, and each nation has a designated responsible agency to ensure compliance.

Without such a top-down instrument like the WMO Convention, the current ocean observing governance system under IOC/UNESCO has become fractured and chronically underfunded. User needs are represented within different UN agencies, ranging from operational users (for example, WMO), scientific users (IOC/UNESCO and International Science Council), and policy/regulatory users (e.g., UN Environment, International Maritime Organization, among others), requiring strong partnerships that are sometimes difficult to establish across agencies.

\section{Bottom-Up Model}

A strength of the bottom-up, community-based self-organizing model is that the governance energy is naturally concentrated in the elements that see the greatest advantage in collaboration. This approach harnesses the energy, enthusiasm, and funding of self-organizing efforts. In this bottom-up model, governance of the global ocean observing system is left to the observing communities to self-organize around their own objectives and goals, but sometimes without the guidance of broader international knowledge, experience and goals. Many of the existing networks, organized around a particular technology for example, were organized by scientists in a bottom-up manner.

This approach could be organized around voluntary participation in an overall governing body financed by membership fees from organizations that would then have a seat at the table of their governance structure. This model could be structured as an independent legal entity and could potentially be inclusive and recognize all participants in ocean observing. An example of this approach is EuroGOOS, the European GOOS Regional Alliance (GRA), that is funded and governed by membership organizations to form a strong regional ocean observing body with well-defined mission and goals.

This bottom-up approach is, to a large extent, already happening with many organizations and structures developing around emerging ocean observing/application themes, networks, and systems. Drawbacks of this approach are lack of coordination and difficulties in access to new technology assessments, best practices, and data sharing globally; the difficulty of accessing advantages provided in the UN system, such as global targets and global/regional development funds; the difficulty of influencing development and implementation of the intergovernmental conventions.

\section{Loosely Coupled Hybrid Model, "Business as Usual”}

The current governance system can be described as a weak "hybrid model" with governance provided by GOOS within the UN system and working as much as possible with partners at all geographic scales. GOOS provides credibility for national and regional observing efforts through its presence within the UN system and by providing member states a voice into the intergovernmental processes.

This loosely coupled model requires stability in order to remain credible and thus effective. Stability and sustainability require long-term commitment to objectives and observing capability, and adequate and appropriate resourcing for the governance model. Resources are currently obtained from funders outside of the UN system for components of the governance system, such as the GOOS panels and most of the network structures. Although this provision of funds from partners outside of the UN system is currently essential to governance operations, it leads to a loosely coordinated, difficult to manage system.

\section{Tightly Coupled Hybrid Model}

This approach is similar to the "business as usual" model, but with a much stronger link for governance partners of the observing system. This model builds on a strong UN presence but with official membership status of partners that work in concert, a hybrid of top-down and bottom-up approaches. Outside of the core activities of coordinating and implementing sustained ocean observing activity, this puts emphasis on building partnerships for delivery, advocacy and visibility with stakeholders, supporting innovation, and developing capacity. A governance approach where partners from the observing system are members and directly participate in governance would facilitate engagement, foster common solutions, and encourage sharing of best practices and data.

How would such an approach look in practice? Perhaps a lead UN agency clearly designated to provide the top-down coordination, plus an office of the lead UN agency placed outside of the UN system as a legal entity that engages the national, regional, scientific, and industry observing partners as members, working in concert with the UN system. It would empower partners to participate and facilitate co-design and management of the observing system.

This starts to define a global common observing governance infrastructure. Though still a small fraction of the investment in observing systems by nations, this approach would give more voice at the intergovernmental level to the national efforts. The benefits of such a global common coordinated infrastructure arguably flow to all nations, but the capacity of many countries to use data for their local purposes must be further developed. The creation of a G7 "Future of Oceans and Seas" working group has led to ongoing discussions of the 
establishment of a G7 sustained ocean observing coordination center, linked to GOOS. This, or a somewhat larger grouping of countries, might form part of a tightly coupled hybrid model for governing GOOS.

\section{Polycentric Multi-Level Governance Systems}

This section seeks to describe the current situation in a framework of multiple centers of responsibility and can be applied to some of the models described above. The situation of multiple centers of responsibility and the lack of an entity or mechanisms with responsibility for overall coordination of the system is common in the world of natural resources governance. Polycentrism is the term given to such system (Ostrom, 2010); they are defined by the existence of multiple centers of influence or decision-making that address a particular problem area. A fully polycentric governance system exists at one end of a "governance modality spectrum" with a central authority system at the other end (Mahon, personal communication). Fully functional polycentric governance systems have some theoretical advantages, including adaptive capacity, fit to institutions, and risk mitigation. Some potential disadvantages are the transactional cost of coordination across structures, and the dispersion of accountability.

Polycentric systems are characterized by having overarching rules, mutual adjustment of activities (collaborate and avoid conflict), a willingness to experiment, trust among members (domains), and are supported by local action of members. Ostrom (2010) considers the benefits of polycentric governance arrangements; "An important lesson is that simply recommending a single governance unit to solve global collective-action problems - because of global impacts - needs to be seriously rethought."

Clearly, the current GOOS governance system is polycentric; there are multiple centers of responsibility for GOOS components, there is a lack of an entity or mechanisms with responsibility for overall for coordination of the system, despite this there are attempts to coordinate and facilitate interaction of existing structures. Significant complications also arise as the GOOS polycentric system is also multilevel, see section Dimensions of Ocean Observing Governance Structures Today.

There are several examples of effective multilevel polycentric governance systems, for instance in the wider Caribbean region (Mahon et al., 2014). There are lessons to be learned from these systems across the observing system. A realization by all actors, that GOOS is a polycentric governance system seems to be an important first step toward moving GOOS toward a co-designed polycentric system. GOOS needs to start with mapping of existing structures, including roles and responsibilities, and then analyze areas of weakness and point to where a focus on improved use of polycentric governance principles is desired. GOOS should use the principles and experience of polycentric multilevel governance systems to evolve toward a more effective system than we have at present.

\section{NEXT STEPS IN OCEAN OBSERVING GOVERNANCE}

GOOS is an organization that includes involvement with in situ networks, satellite systems, governments, UN agencies, research organizations, individual scientists, design engineers, and data managers. GOOS adopted and oversees the FOO guidelines which have been widely embraced and used throughout the ocean observing community. Through the FOO, GOOS is coordinating the assessment of ocean observing requirements, observing system implementation, and innovation through GOOS Projects. Sitting within the UN structure allows GOOS to enable a 2way interaction with nations through many forums. By building community consensus, GOOS enables stakeholders to engage with the system as a whole.

Since its establishment the GOOS mandate has grown in size to include multiple scientific disciplines, responding to a growing range of societal and policy drivers, and operating in an increasingly crowded governance landscape. In 2019, the "global ocean observing system" brings together individuals and organizations from multiple inter-governmental organizations (e.g., UN Conference of the parties to the Framework Convention on Climate Change, UNESCO-IOC, WMO, UN Environment, European Community), and national and academic sectors from more than one hundred countries.

The authors conclude that a polycentric governance model is appropriate for GOOS, and that a set of Principles should be agreed to ensure the basis for this model aligns with stakeholder needs and expectations. We further think that the model would include governance action at the global, basin, regional and local/national levels, coordinated according to polycentric methods; not all nations, regions or basins need be explicitly represented, but their needs must be. GOOS governance should be recognized within the UN and intergovernmental system, but may need some separation to fulfill ideals of responsiveness and adaptability.

\section{Call to Action}

- We invite all participants across the ocean observing community to consider and comment on the governance ideas laid out in this paper. Leading up to the OceanObs19 conference a concerted effort will be conducted to collect input on the governance recommendations from across the community. This process will be designed to make feedback into the process as seamless as possible while providing a forum for ongoing discussion and comment.

- Further, as these governance discussions will be an important part of the agenda at OceanObs19 in September 2019 , to ensure the community is ready to make meaningful progress on this issue at those meetings, a series of workshops will be held beforehand (in early to mid2019) with invitations to representatives of all the varied parts of the observing community. The workshop agenda will address various ways to improve communication, coordination, partnership and governance across the global ocean observing enterprise. 


\section{AUTHOR CONTRIBUTIONS}

TT, AM, and AF helped to conceive the study, coordinated the author contributions, wrote and edited the manuscript, and contributed to tables and figures. LG, LS, and AM coordinated the submission of manuscript, completion of tables and figures, and final report editing. WA, NB, KC, BD, DD, EH, JG, KH, MI, DL, EL, PM, TM, GN, AP, SS, BS, NS, MT, MV, and JW contributed to the manuscript ideas and text.

\section{FUNDING}

Preparation of this manuscript was supported by 80NSSC17M0007 (NASA) University Corporation for Atmospheric Research (UCAR). Some recommendations from this work resulted from PEGASuS 2: Ocean Sustainability, a partnership between Future Earth, the National Center

\section{REFERENCES}

Bax, N. J., Appeltans, W., Brainard, R., Duffy, J. E., Dunstan, P., Hanich, Q., et al. (2018). Linking capacity development to GOOS monitoring networks to achieve sustained ocean observation. Front. Mar. Sci. 5:346. doi: 10.3389/fmars. 2018.00346

Cravatte, S., Kessler, W. S., Smith, N., and Wijffels, S. E. (2016). First Report of TPOS 2020. GOOS-215, 200. Available at: http://tpos2020.org/first-report/

de Young, B., Visbeck, M., de Araujo Filho, M. C., Baringer, M. O., Black, C. A., Buch, E. et al. (2019). An integrated all-atlantic ocean observing system in 2030. Front. Mar. Sci. 26. doi: 10.3389/fmars.2019.00428

IOC (2019). The Global Ocean Observing System 2030 Strategy. Paris: IOC. 2019.

Jachtenfuchs, M., and Krisch, N. (2016). Subsidiarity in global governance. Law Contemp. Probl. 79, 1-26.

Levin, L. A., Bett, B. J., Gates, A. R., Heimbach, P., Howe, B. M., Janssen, F., et al. (2019). Global observing needs in the deep ocean. Front. Mar. Sci. 6:241. doi: 10.3389/fmars.2019.00241

Lindstrom, E., Gunn, J., Fischer, A., McCurdy, A., Glover, L., Alverson, K., et al. (2012). A Framework for Ocean Observing. By the Task Team for an Integrated Framework for Sustained Ocean Observing. Paris: UNESCO. doi: 10.5270/ OceanObs09-FOO

Mahon, R., Fanning, L., Gjerde, K., Young, O., Reid, M. R., and Douglas, S. (2014). "Governance," in The Open Ocean: Status and Trends, eds UNESCO, IOC, and UNEP (Nairobi: United Nations Environmental Program), 21-45.

Miloslavich, P., Bax, N. J., Simmons, S. E., Klein, E., Appeltans, W., AburtoOropeza, O., et al. (2018a). Essential ocean variables for global sustained observations of biodiversity and ecosystem changes. Glob. Change Biol. 24, 2416-2433. doi: 10.1111/gcb.14108

Miloslavich, P., Seeyave, S., Muller-Karger, F., Bax, N., Ali, E., Delgado, C., et al. (2018b). Challenges for global ocean observation: the need for increased human capacity. J. Operat. Oceanogr. 11, 1-20. doi: 10.1080/1755876X.2018.15 26463 for Ecological Analysis and Synthesis (NCEAS), and Global Biodiversity Center at Colorado State University. TT and AP acknowledges support from EU's Horizon 2020 Research and Innovation Program under grant agreement 63321 (AtlantOS). MT acknowledges support from the US National Science Foundation grant OCE-1840868 to the Scientific Committee on Oceanic Research (SCOR, US).

\section{ACKNOWLEDGMENTS}

We thank many people who contributed to the preparation of the 2012 Framework for Ocean Observing, the GOOS 2030 Strategic Plan, and the multitude of Project Reports, Annual Reports, Conference Proceedings, and Blueprint documents referenced in this White Paper. All of their efforts and energy contributed to the ideas and expertise herein.

Ostrom, E. (2010). Polycentric systems for coping with collective action and global environmental change. Glob. Environ. Change 20, 550-557. doi: 10.1016/j. gloenvcha.2010.07.004

Pearlman, J., Bushnell, M., Coppola, L., Karstensen, J., Buttigieg, P. L., Pearlman, F., et al. (2019). Evolving and sustaining ocean best practices and standards for the next decade. Front. Mar. Sci. 6:277. doi: 10.3389/fmars.2019. 00277

Smith, N., Kessler, W. S., Cravatte, S., Sprintall, J., Wijffels, S., Cronin, M. F., et al. (2019). Tropical pacific observing system. Front. Mar. Sci. 6:31. doi: 10.3389/ fmars.2019.00031

Tanhua, T., Pouliquen, S., Hausman, J., O’brien, K., Bricher, P., Bruin, T. D., et al. (2019). Ocean FAIR data services. Front. Mar. Sci. (in press).

Wilkinson, M. D., Dumontier, M., Aalbersberg, I. J., Appleton, G., Axton, M., Baak, A., et al. (2016). The FAIR guiding principles for scientific data management and stewardship. Sci. Data 3:160018. doi: 10.1038/sdata.2016.18

Conflict of Interest Statement: LS was employed by company Your Ocean Consulting, LLC, and LG was employed by company Glover Works Consulting.

The remaining authors declare that the research was conducted in the absence of any commercial or financial relationships that could be construed as a potential conflict of interest.

Copyright (C) 2019 Tanhua, McCurdy, Fischer, Appeltans, Bax, Currie, DeYoung, Dunn, Heslop, Glover, Gunn, Hill, Ishii, Legler, Lindstrom, Miloslavich, Moltmann, Nolan, Palacz, Simmons, Sloyan, Smith, Smith, Telszewski, Visbeck and Wilkin. This is an open-access article distributed under the terms of the Creative Commons Attribution License (CC BY). The use, distribution or reproduction in other forums is permitted, provided the original author(s) and the copyright owner(s) are credited and that the original publication in this journal is cited, in accordance with accepted academic practice. No use, distribution or reproduction is permitted which does not comply with these terms. 